\title{
A coordenação pedagógica como elemento de interseção das diferenças culturais
}

\author{
The pedagogical coordination as an element of intersection of cultural
}

differences

Cristiano Sant'anna

Doutor em Educação pela Universidade do Estado do Rio de Janeiro. Vice-coordenador e pesquisador do Grupo Kéreré pelo Programa de Pós-graduação em Educação da Universidade do Estado do Rio de Janeiro e Conselho Nacional de Desenvolvimento Científico e Tecnológico, Rio de Janeiro, RJ, Brasil cs-medeiros@uol.com.br

Isadora Souza da Silva Doutoranda em Educação pela Universidade do Estado do Rio de Janeiro. Diretora da Rede Municipal de Educação do Rio de Janeiro, RJ, Brasil. isadora24@bol.com.br

Resumo: O ensaio aborda como o trabalho de coordenadores pedagógicos pode ser considerado como elo constitutivo no processo de respeito às diferenças dentro do ambiente escolar. A investigação aponta a existência de marcos interculturais em espaços escolares onde a figura do coordenador pedagógico é fator de suma importância para integração e efetivação da e na dinâmica educacional. Serão analisados, a partir de referenciais teóricos do multiculturalismo e da interculturalidade crítica, a implementação de projetos artísticos culturais numa unidade educacional pública do Rio de Janeiro. Tal projeto é fruto da parceria entre a unidade educacional e uma instituição sem fins lucrativos. Para além das questões políticas que tal parceria possa vir a suscitar, o foco da investigação, aqui presente, se limita a analisar como os projetos se constituíram, qual a sua relevância para o cotidiano escolar e as relações nele tecidas e a importância do papel da coordenação pedagógica em todo o processo.

Palavras-chave: Coordenação Pedagógica. Cultura. Projetos Sociais.

Abstract: The essay aims to address how the work of pedagogical coordinators can be considered as a constitutive link in the process of respecting differences within the school environment. The proposed research points to the existence of intercultural frameworks in school spaces, where the pedagogical coordinator is a very important factor for the integration and effectiveness of and in the educational dynamics. From the theoretical references of multiculturalism and critical interculturalism, the implementation of two cultural artistic projects in a public educational unit in the city of Rio de Janeiro will be analyzed. These projects are fruits of the partnership between the educational unit and a non-profit institution. In addition to the political issues that such a partnership may bring about, the focus of research here is limited to analyzing how the projects were constituted, what their relevance is to the school daily life and the relationships they have in it and the importance of the role of pedagogical coordination in all process.

Keywords: Culture. Pedagogical Coordination. Social Projects. 


\section{Introdução}

O presente ensaio pretende abordar como o trabalho de Coordenadores Pedagógicos pode ser considerado como elo constitutivo no processo de respeito às diferenças dentro do ambiente escolar. A investigação proposta aponta a existência de marcos interculturais em espaços escolares onde a figura do coordenador pedagógico é fator de suma importância para integração e efetivação da e na dinâmica educacional. Será analisada, a partir de referenciais teóricos do multiculturalismo e da interculturalidade crítica, a implementação de um projeto artístico cultural em uma unidade educacional pública no município do Rio de Janeiro. Tal projeto é fruto da relação denominada como parceria entre a unidade educacional (U.E.) e uma instituição sem fins lucrativos. Para além das questões políticas que tal parceria possa vir a suscitar, o foco da investigação, aqui presente, se limita a analisar como o referido projeto se constituiu, qual a sua relevância para o cotidiano escolar e relações nele tecidas e a importância do papel da coordenação pedagógica em todo o processo.

Apresentaremos o trabalho desenvolvido pelas duas instituições - escola e Organização Não Governamental ${ }^{1}$ - com as crianças da U.E. localizada numa área conflagrada da cidade. A proposta diz respeito à formação do grupo artístico cultural, Coral de Vozes dos alunos da Nova Holanda. Tal iniciativa pode ser considerada como expressão de micropolíticas públicas em educação, organizada e gerenciada pelos diferentes atores do cotidiano escolar, em especial a equipe pedagógica, na tentativa de ampliação e diferenciação do currículo mínimo proposto à rede educacional do município antes citado, com a intenção de promover o contato inicial e/ou continuado dos alunos de escolas públicas de regiões periféricas com os diversos tipos de arte, assim como a valorização e o diálogo com as culturas locais.

\section{O local da cultura no Complexo da Maré}

No espaço simbólico de culturas diferentes, instituições se estruturam - entre estas, a escola - e as relações tecidas nesse ambiente são forjadas a partir de valores culturais ou de valores culturalmente estabelecidos. A dinâmica da discussão a respeito das diferenciações culturais, nas duas últimas décadas, se fez presente na literatura que discorre sobre o debate

\footnotetext{
${ }^{1}$ Organizações Não Governamentais são instituições sem fins lucrativos, caracterizadas por trabalhos sociais, ambientais e humanísticos. Faremos referência delas, no texto, pela sigla ONG, forma como são usualmente identificadas.
} 
educacional, assim como algumas expressões atuais do cenário educacional brasileiro, que apontam para um caminho onde o respeito à diferença, à pluralidade cultural e, com base na diversidade de raça, gênero e classe social, ressaltam a necessidade de trabalhar temas transversais que integrem culturas distintas, diminuindo preconceitos e intolerâncias e apontando caminhos para um ideal de currículo intercultural.

Apesar das diferenças dos espaços geográficos e sociais, tão diversificados no território brasileiro, é recorrente encontrar nas falas dos diferentes atores educacionais, tomando como referencial a pesquisa acadêmica, dificuldades em enxergar a cultura como terreno central do processo curricular, assim como os embates consequentes da pluralidade cultural encontrada nos cotidianos escolares.

Fica explícito que, nos debates acerca da organização curricular, em especial de escolas públicas de periferias, existiam tensões oriundas dessa pluralidade, frequentemente geradoras de conflitos, que poderiam transformar-se em práxis de enriquecimento e renovação da atuação docente.

Para tanto, pode-se vivenciar, na prática, implicações subjacentes à diversificação cultural num ambiente e currículo escolares e perceber o quanto a participação da coordenação pedagógica pode ou não corroborar práticas interculturais exitosas.

O Complexo da Maré é um conjunto de 17 comunidades, localizado na zona norte da Av. Brasil, importante avenida que corta parte do Rio de Janeiro, da zona portuária até o extremo oeste do município, ligando-o aos municípios limítrofes e outras grandes rodovias. Sua localização é privilegiada uma vez que se encontra próximo da região central e comercial do município e pela vasta oferta de transporte público que circula na região.

As comunidades desse Complexo estão cercadas pela Av. Brasil, citada acima, e pela Baía de Guanabara, motivo pelo qual foi batizado com esse nome na década de 1960, no então governo de Carlos Lacerda. Por se tratar de uma região localizada sobre um aterro do Parque Maré, suas primeiras edificações eram invadidas, constantemente, pelo nível da água quando a maré subia e, por isso, uma das maiores e mais conhecidas favelas do Complexo foi batizada como Nova Holanda em alusão ao país europeu localizado abaixo do nível do mar.

Outros fatores sociais e econômicos contribuíram para a construção de parte do imaginário coletivo sobre esse conjunto de favelas, assim como a de tantas outras. A falta da presença do poder público, traduzido em descaso com os moradores da região, corroborou para que o tráfico de drogas, configurado em um poder paralelo, se estruturasse nessa área, tornando-a um lugar pouco amistoso. A carência de uma favela não se encontra apenas no fator econômico, 
talvez ele seja o precursor. Faltam serviços básicos de moradia, saneamento básico, saúde, lazer e cultura. Não existem aparelhos culturais no interior de uma favela (cinema, teatros, bibliotecas). Os poucos que existem, atualmente, são frutos de um trabalho militante de atores sociais, moradores ou ex-moradores dessas localidades, apoiados ou não por empresas privadas. Mas, existem escolas!

Assim como o tráfico de drogas se aproveitou das brechas do poder público para se instalar e fazer suas próprias leis nos territórios dos quais se apropriaram, a arte e a cultura também subverteram essa lógica cruel e excludente e criaram seus espaços e seus movimentos próprios. O funk carioca, que hoje toca e faz as pessoas dançarem até o chão em todo o país, nasceu das ruas e becos das favelas. Aos moradores e viventes de espaços renegados pelo poder público, se nada lhes for oferecido, eles criarão. E, assim, a cultura das favelas ganhou o mundo. Mas, ainda há escolas!

\section{A escola e a dialogicidade da cultura em favelas}

No complexo e plural universo da Maré, existem mais de 44 unidades educacionais públicas, entre creches, Espaços de Desenvolvimento Infantil (EDIs) e escolas de ensino fundamental. Se compararmos esses dados aos da Secretaria de Saúde e aos das demais secretarias municipais atuantes nessa localidade, podemos concluir que a educação é a representação do Estado nas favelas do Rio de Janeiro.

E como a Escola - por tudo que ela representa na e para a formação intelectual de seus alunos - pode contribuir, dialogar e corroborar com as diferentes e genuínas expressões culturais que advêm das favelas? Como a instituição escolar, com seu caráter de promotora cultural, pode não silenciar seus diferentes sujeitos, da mesma forma, que não lhe cabe negar diferentes conhecimentos? É o que tentaremos relatar a partir de agora.

No ano de 2016, uma das unidades de ensino fundamental localizada na Comunidade da Nova Holanda, Complexo da Maré, iniciou um projeto piloto com alunos da faixa etária de 8 a 12 anos. O projeto era de educação musical e culminaria no Coral de Vozes da Nova Holanda. A ideia surgiu da equipe pedagógica da U.E., que já mantinha estabelecida uma proposta de parceria com o Projeto "Sabendo Mais", entidade sem fins lucrativos atuante na comunidade local, que oferecia no espaço escolar, no horário da instituição, aulas de conhecimentos diversos que a matriz curricular da rede não previa, tais como dança, música, psicomotricidade, entre outras. As 
atividades eram escolhidas pelos próprios alunos a partir de seus interesses. Nesse sentido, acreditávamos estar respeitando a pluralidade das identidades e a construção delas, do mesmo modo que construíamos um novo currículo a partir destas ideias e experiências. Alunos e professores/dinamizadores enxergavam, nesse espaço, uma possibilidade de nova configuração escolar.

A função da coordenação pedagógica era a de articular os saberes do currículo oficial, trabalhado na escola, com as diversas linguagens apresentadas no Projeto "Sabendo Mais", entre elas, a educação musical e a dança. Essas linguagens eram mediadas por professores do próprio Projeto no espaço escolar da U.E. e dentro do horário de aula. Essa unidade, desde o ano de 2016, passou a funcionar em horário integral a partir de uma demanda da própria rede municipal. Com o aumento da carga horária diária das crianças na escola, foi possível pensarmos uma dinâmica diversificada e ampliação também do currículo formal.

As equipes envolvidas na criação e implementação da proposta, acreditando na importância das artes no processo formativo dos alunos, entendendo que cabe à escola promover o acesso a diferentes patrimônios e expressões culturais, que nem sempre são veiculadas na comunidade onde a escola está localizada e, consequentemente, distanciada do conhecimento de nossas crianças, enxergou nessa proposta uma forma de fomentar o diálogo entre diferentes expressões culturais, fazendo do espaço escolar um lugar de dinâmica e diálogo de diferentes culturas, sem hierarquizações e/ou classificações qualitativas.

Optou-se por conhecimentos e expressões que fossem atravessados pela música, por isso, um coral e a dança. Acredita-se que a música é uma linguagem universal, que ultrapassa as barreiras do tempo e do espaço. É incontestável que a música se faz presente na vida dos seres humanos, independente da época ou de gerações, e exerce diferentes funções na sociedade, independentemente do tempo e das diferentes culturas. Diversas literaturas sustentam a importância da música para o desenvolvimento cognitivo das crianças, assim como o seu impacto nas diferentes áreas de conhecimento. Em especial, na atualidade, a música assume relevante papel na comunicação, segundo o pedagogo Snyders (1992), nunca uma geração viveu tão intensamente a música como as atuais. Diferentes pesquisadores de todo mundo - Gardner (1994); Kramer e Leite (1998); Nogueira (1994, 2001); Porchet (1982); Ilari e Broock (2013) -, desde o final do século 20, afirmam que a influência da música, no desenvolvimento da criança, é incontestável desde o útero materno onde bebês reagem a estímulos sonoros. Além de possibilitar estímulos, a música também assume caráter relaxante, ajudando na absorção de 
informações e ampliando a capacidade de concentração, isto é, a música interfere diretamente no processo de aprendizagem.

Acreditando no poder transformador da música e no quanto ela pode ser significativa para as crianças na idade escolar, amparados pela Lei $n^{\circ} 11.769 / 2008$, a escola pesquisada iniciou, no ano de 2016, em parceria com o Projeto "Sabendo Mais", aulas de iniciação musical (teoria e prática) com os alunos dos primeiros anos do ensino fundamental, objetivando desenvolver a criatividade, a sensibilidade e a integração de nossos alunos, ampliando, assim, seus repertórios culturais. Além da iniciação musical, a partir do primeiro ano, uma audição foi realizada com todos os alunos da escola, que demostraram interesse em participar do coral. O objetivo era familiarizar as crianças, desde o primeiro ano do ensino fundamental, com a teoria musical para que, quando chegassem ao terceiro ano, pudessem passar pelas audições, tendo um conhecimento prévio.

A escola, sendo uma instituição moderna, historicamente construída nos pilares da cultura, tem, como função social fundamental, transmitir e oferecer às novas gerações o que de mais significativo produziu a humanidade, culturalmente. Entretanto, é importante observar que, no interior dela, também se faz presente uma cultura própria, pautada e baseada nas culturas locais que a cercam e na própria cultura forjada em seu interior a partir de seus sujeitos. É nesse processo híbrido e dialético que identidades são criadas. Por isso, a pertinência das ideias aqui expostas, que enxergam nessa iniciativa de política pública uma possibilidade de contato e reconhecimento de expressões artísticas, que fogem do lugar comum e, com isso, vislumbram a possibilidade de construção e ampliação de currículo crítico, tendo, como eixo norteador, as pessoas responsáveis em fazer essas diferentes culturas dialogarem e se respeitarem: a equipe diretiva e a coordenadora pedagógica.

Se para os estudos culturais, o conceito de cultura é visto como campo de luta onde significados são negociados e construídos, a escola e seu currículo, assim como seus atores, são partes pertencentes dessa arena. Então, a importância de pensar sobre as mudanças de postura e novos olhares para essa escola, seus conhecimentos produzidos tanto no seu interior quanto no seu entorno, na desconstrução do papel docente de transmissores de informação e de uma única cultura para produtores e críticos culturais que enxergam novos horizontes (MOREIRA; CANDAU, 2007).

É possível perceber as tensões culturais dialogando nesse processo à medida que analisamos tal proposta; proposta esta que já se caracteriza como dialógica em sua estruturação, organização e logística. Estamos referindo-nos a um projeto de incentivo e promoção às artes, 
em sua maioria, de cunho clássico, que acontece em unidades educacionais de uma região periférica de uma grande cidade onde a população, na maioria, não tem acesso a bens culturais, mas que, por sua vez, se tornam produtores e consumidores de uma cultura própria, local. A proposta acontece em espaços escolares, porém, não funciona a partir do currículo escolar formal, mas sim, com atividades diferenciadas, utilizando os espaços físicos e temporais diferentes dos habituais.

Contudo, tal iniciativa suscita algumas questões: Como, de fato, acontece esse diálogo? Como acontece a hibridização de diferentes culturas nesse contexto? Tal proposta pode ser usada como paradigma para construção de um currículo intercultural? Qual é o papel da equipe pedagógica nesse processo?

A proposta pedagógica, trabalhada nesse Projeto, é uma experiência de coragem e, como diria Certeau (2014), de astúcia, pois traça um currículo diferenciado em que é perceptível o incentivo à aproximação de linguagens artísticas locais e globais. Essa forma de trabalhar possibilita investigar o conceito de culturas híbridas à luz das narrativas de Bhabha (1998):

\footnotetext{
Uma linguagem híbrida, ou seja, aquela que cruze as fronteiras culturais, incorporando discursos múltiplos, reconhecendo a pluralidade e a provisoriedade de tais discursos e promovendo sínteses interculturais e criativas. A linguagem hibrida busca superar os congelamentos identitários e as metáforas preconceituosas, levando uma descolonização dos discursos, central para práticas pedagógicas valorizadoras do múltiplo, do plural e do diverso (BHABHA,1998, p. 21).
}

Canclini (1995, p. 19) conclui "que todas as fronteiras e que as artes, em virtude do fenômeno de desterritorialização, articula-se em relação umas às outras, sendo-lhes possível, com isso, ampliar seu potencial de comunicação e conhecimento". Procura-se, portanto, entender em que medida uma proposta curricular direcionada a grupos específicos de crianças e adolescentes, moradores da periferia de um grande centro urbano, contribui na formação de identidades multiculturais. Esse projeto, acontecendo no interior de uma escola, quais reflexos incidem no processo de ensino-aprendizagem desses alunos?

Tomando como base as contribuições dos estudos da cultura, fica clara a relação da escola enquanto instituição cultural. Segundo Moreira e Candau (2003), a escola é uma instituição cultural; as relações tecidas em seu interior são culturais e não podem ser concebidas como dois polos independentes, "mas sim como um universo entrelaçado, como uma teia tecida no cotidiano com fios e nós profundamente articulados" (MOREIRA; CANDAU, 2003, p. 160).

Entender a escola como terreno de hibridização cultural e identitária, sugere rompermos com a concepção de tradição monocultural, abrindo espaços para a valorização das diferenças 
sem deixar, contudo, ludibriar-se por discursos efêmeros que, ao contrário do que parece, acaba por reforçar determinados preconceitos, como nos alertam Canen e Canen (2005):

Por exemplo, no que se refere à abordagem liberal ou folclórica, em que medida a melhoria das relações pessoais entre indivíduos, a partir de trabalhos que visam a "conhecer melhor" suas tradições, formas de ver o mundo e outras manifestações culturais, não estariam mascarando relações desiguais e preconceituosas que marcam a construção dessas identidades? Ao mesmo tempo, ao jogar luzes sobre racismos, sexismos e outros preconceitos, como nas abordagens mais críticas, em que medida o multiculturalismo crítico não recai em uma exaltação da diferença e no reforço a preconceitos? (CANEN; CANEN, 2005, p. 42).

No entanto, foi perceptível o esforço da equipe pedagógica em romper com algumas barreiras impostas pelas políticas formais ao conseguir colocar em prática uma agenda que valoriza as diferentes culturas que circulam no espaço delimitado da escola e, acima de tudo, reverbera todo o contexto do seu entorno, o que seria definido por Boaventura de Souza Santos (2001) como multiculturalismo emancipatório, que busca a compreensão das diferenças dentro das diferenças.

É fundamental que o multiculturalismo emancipatório, ao contrário, parta do pressuposto que as culturas são todas elas diferenciadas internamente e, portanto, é tão importante reconhecer as culturas umas entre as outras, como reconhecer diversidade dentro de cada cultura e permitir que dentro da cultura haja resistência, haja diferença (SANTOS, 2001, p. 33).

Essa postura fazia com que as coordenadoras pedagógicas estimulassem seus professores e dinamizadores a enxergar, nas contribuições dos diferentes pontos de vista, um enfrentamento desses problemas e, consequentemente, suas superações, desafiando dogmas impostos e visões encapsuladas, marcadas ideologicamente pelo preconceito em relação às diferenças e pela necessidade obscurantista de impor condutas e padrões uniformes sobre a realidade.

\section{A coordenação pedagógica como marco diferencial de experiências exitosas}

Ao longo do século passado, aconteceram movimentos e debates que pautaram a ocorrência de uma revolução cultural denominada "Virada Cultural" em que a cultura deixou de ser concebida como um somatório de saberes ou processos estéticos e elitistas e passou a ser analisada e compreendida, levando-se em conta a gama de relações que a ela estão associadas. A Virada Cultural traz, então, para o terreno das discussões, a necessidade de compreender os mecanismos de regulação e poder, que autorizam certos discursos e silenciam outros. 
Em meio a movimentos de grupos sociais, que buscam apropriar-se de instrumentais e ferramentas conceituais, negando os discursos seculares sectários e segregadores, que se encontram ansiosos por uma cultura pautada em oportunidades democráticas numa educação de livre acesso em que pessoas comuns pudessem ser reconhecidas e ter seus saberes valorizados e interesses contemplados, surgem os estudos culturais, inicialmente em Birmingham, Inglaterra, tendo Stuart Hall (1997) como um de seus precursores, que aponta:

\footnotetext{
Por bem ou por mal, a cultura é agora um dos elementos mais dinâmicos - e mais imprevisíveis - da mudança histórica no novo milênio. Não deve nos surpreender, então, que as lutas pelo poder sejam, crescentemente, simbólicas e discursivas, ao invés de tomar, simplesmente, uma forma física e compulsiva, e que as próprias políticas assumam progressivamente a feição de uma política cultural (HALL, 1997, p. 97).
}

É nesse cenário plural, nessa complexidade de relações de significados, nessa sociedade que enxerga, não só uma única cultura, mas que dá voz e vez à diversidade cultural, denotando as diferenças a respeito das etnias, nacionalidades, sexualidades e gerações, que a escola está inserida. Seus diferentes atores são pessoas e sujeitos viventes dessas mais diversas culturas. Reconhecer a pluralidade desse espaço talvez seja um dos primeiros requisitos para a construção de uma experiência exitosa. A escola não é nem está apartada da sociedade: ela é a sociedade.

A compreensão desse primeiro fator foi determinante para que as diferentes equipes coordenadoras, escola e ONG pudessem dar continuidade a todo o processo, motivando professores e alunos, trazendo-os para a construção coletiva dos temas geradores em concordância com os projetos da escola. A aceitação e envolvimento de pais e responsáveis, o reconhecimento da Coordenadoria de Educação e da Secretaria Municipal de Educação, ambas da cidade do Rio de Janeiro, eram indicativos de que estavam no caminho certo. Para, além disso, talvez o fator de maior importância se revelou como satisfatória a atuação do Projeto num espaço escolar como forma de promoção de conhecimento e contato com as artes, valorizando e reconhecendo as identidades, as diferenças, e promovendo o diálogo entre as diversas culturas.

A partir do acompanhamento de todo o processo de implementação da proposta, é possível entender a pertinência da atuação em práticas pedagógicas multiculturalmente orientadas, de projetos culturais que aconteçam em espaços escolares, bem como a possibilidade de diálogo entre estes e os demais segmentos escolares por meio de hibridizações. Hibridizações estas, promovidas e estimuladas por fazeres pedagógicos, pelos profissionais que têm a função de articular os diferentes saberes, as diferentes práticas, a diversidade de conhecimentos: os coordenadores pedagógicos. A escola se torna, pouco a pouco, nessa abordagem, um espaço de 
resistência na medida em que valoriza as diferentes culturas - local e global - num movimento intercultural.

Almeja-se que o relato em tela possa corroborar a promoção de práticas pedagógicas, voltadas para o incremento do diálogo discente/docente, popular/erudito, local/global e o reconhecimento de que as diferenças não precisam ser dissipadas dos processos educacionais, mas sim, identificadas como fundamentais ao processo de construção das identidades, e que o trabalho da coordenação pedagógica possa ser reconhecido como elo de interseção dessas diferentes dinâmicas.

Cultura é, portanto, algo que se constrói e se mistura. Influências musicais, visuais, de moda, de cinema e outros, têm, na escola, o espaço ideal para serem apresentadas e desenvolvidas, inseridas em um currículo flexível e que se atualiza de acordo com as necessidades da comunidade escolar. E precisam ter, em seus atores, os sujeitos construtores dessas diferentes expressões, sejam eles alunos, professores ou coordenadores.

\section{Considerações finais}

A discussão, ora apresentada, objetiva uma análise de iniciativas socioculturais que, hoje, acontecem em espaços escolares, especificamente na Rede Municipal de Educação do Rio de Janeiro, em especial, no Complexo da Maré. Essa, é fruto de um processo de parceria entre uma unidade educacional pública e uma ONG, ou seja, híbrida, por formação.

Tal proposta visa promover o contato de alunos da rede pública desse município com diferentes expressões de arte/cultura, valorizando o que denominamos de entre lugares (BHABHA, 1998), em alusão a estudos pós-colonialistas e culturais. O que nos interessa, no presente trabalho, é entender como os encontros das diferentes narrativas, traduzidas em expressões artístico-culturais são teoricamente inovadoras e politicamente cruciais para pensarmos na superação (e não no apagamento, aniquilamento ou desrespeito) das subjetividades iniciais e, assim, alcançarmos momentos ou processos que são produzidos na articulação de diferenças culturais. A ponte que reúne enquanto passagem que atravessa.

Se aceitarmos que a escola não é uma arena imparcial e que, em seu interior, ocorrem disputas pelo poder de enunciação de uma história que é comum, mas que, antagonicamente, situa cada grupo em um determinado lugar, diferente e desigual, devemos considerar que qualquer mudança no currículo será pautada por lutas políticas, e não pode ser pensada como 
apenas incorporação de conteúdos que serão somados, pacificamente, aos já existentes. Para que essa possibilidade se concretize e seja possível a ampliação de atividades que respeitem as diferenças culturais, o currículo oficial precisa passar também por reformulação no sentido de traçar paralelos entre os conhecimentos tradicionais e temas transversais, valorizando as possíveis aproximações e trocas culturais, como preconiza a Declaração Universal sobre a Diversidade Cultural (UNESCO, 2001). E nada disso será possível de realização se não houver lideranças nos espaços escolares que reúnam esses diferentes saberes senão a equipe pedagógica.

\section{Referências}

BHABHA, H.K. O local da cultura. Belo Horizonte: UFMG, 1998.

BRASIL. Lei no 11.769, de 18 de agosto de 2008. Altera a lei no 9.394, de 20 de dezembro de 1996, Lei de Diretrizes e Bases da Educação, para dispor sobre a obrigatoriedade do ensino de música na educação básica. Diário Oficial da União, Brasília, DF: 2008. Disponível em: <http://www.planalto.gov.br/ccivil_03/_ato2007-2010/2008/lei/111769.htm>. Acesso em: 01 maio 2018.

CANCLINI, N.G. Culturas híbridas: estrategias para entrar y salir de la modernidad. Buenos Aires: Sudamericana, 1995.

CANEN, A.; CANEN, A.G. Rompendo fronteiras curriculares: multiculturalismo na Educação e outros campos de saber. Revista Curriculo sem Fronteiras, v. 5, n. 2, p. 40-49, Jul/Dez. 2005.

Disponível em: $<$ http://www.curriculosemfronteiras.org/vol5iss2articles/canen.pdf $>$. Acesso em: 03 dez. 2018.

CERTEAU, Michel. A invenção do cotidiano: artes de fazer. 22 ed. Petrópolis, RJ: Vozes, 2014.

GARDNER, Howard. Estruturas da mente: a teoria das inteligências múltiplas. Porto Alegre: Artes Médicas, 1994.

HALL, Stuart. Identidades culturais na pós-modernidade. Rio de Janeiro: DP\&A, 1997.

ILARI, Beatriz; BROOCK, Angelita (Orgs.). Música e educaşão infantil. Campinas, SP: Papirus, 2013.

KRAMER, S.; LEITE, M.I. (Orgs.) Infância e produção cultural. Campinas, SP: Papirus, 1998.

MOREIRA, Antonio Flávio Barbosa; CANDAU, Vera Maria. Educação escolar e cultura(s): construindo caminhos. Revista Brasileira de Educação. Rio de Janeiro, n. 23, p. 156-168, maio-ago., 2003. Disponível em: < http://www.scielo.br/pdf/rbedu/n23/n23a11.pdf > . Acesso em: 03 dez. 2018.

MOREIRA, Antonio Flávio Barbosa; CANDAU, Vera Maria. Indagações sobre currículo: currículo, conhecimento e cultura. Organização do documento: Jeanete Beauchamp, Sandra Denise Pagel, Aricélia Ribeiro do Nascimento. Brasilia: Ministério da Educação, Secretaria de Educação Básica, 
2007. 48 p. Disponível em: <http://portal.mec.gov.br/seb/arquivos/pdf/Ensfund/indag3.pdf> Acesso em: 01 maio 2018.

NOGUEIRA, Monique Andries. A formação do ouvinte: um direito do cidadão - proposta para educação musical no Ensino Fundamental. 117 f. Dissertação (Mestrado em Educação) Universidade Federal de Goiás, Faculdade de Educação, Goiânia, 1994. Disponível em: $<$ https://ppge.fe.ufg.br/up/6/o/Dissert - Monique Andries Nogueira.pdf $>$. Acesso em: 03 dez. 2018.

NOGUEIRA, Monique Andries. Música, consumo e escola: reflexões possíveis e necessárias. In: RAMOS-DE-OLIVEIRA, Newton; ZUIN, Antônio Álvaro Soares;

PUCCI, Bruno (Orgs.). Teoria crítica, estética e educaşão. Campinas, SP: Autores Associados; Piracicaba, SP: Unimep, 2001. p. 185-95.

PORCHER, Louis. Educação Artística: luxo ou necessidade? 7 ed. São Paulo: Summus, 1982.

SANTOS, Boaventura de Souza. Dilemas do Nosso Tempo: globalização, multiculturalismo e conhecimento. Entrevistadores: Luís Armando Gandin; Álvaro Moreira Hypolito. Educaşão e Realidade, Porto Alegre, v. 26, n. 1, p. 13-32, jan./jul. 2001. Disponível em: $<$ https://seer.ufrgs.br/educacaoerealidade/article/view/41311>. Acesso em: 03 dez. 2018.

SNYDERS, Georges. A escola pode ensinar as alegrias da música? São Paulo: Cortez, 1992.

UNESCO. Declaração Universal sobre a Diversidade Cultural. 2001. Disponível em: < http://www.unesco.org/new/fileadmin/MULTIMEDIA/HQ/CLT/diversity/pdf/declaration cultural diversity pt.pdf $>$. Acesso em: 01 maio 2018.

Recebido em: 23 mai. 2019 / Aprovado em: 21 nov. 2019

Cite como

SANT'ANNA, Cristiano; SILVA, Isadora Souza da. A coordenação pedagógica como elemento de interseção das diferenças culturais. Dialogia, São Paulo, n. 33, p. 131-142, set./dez. 2019. Disponível em: https://doi.org/10.5585/Dialogia.n33.13969. 